\title{
Trabalho, Cultura e Administração
}

\author{
Prof. Humberto Grande \\ Procurador Geral da Justiça do Trabalho
}

$\mathrm{P}$ cação, é mister polarizá-lo cơm os diferentes valores culturais .

Assim devemos relacionar. sob todos os pontos de vista, a administração com a ciência, com a arte, com a técnica, com a moral, e enfim, com a filcsofia. Dentre dessa orientação segura, lançaremos os fundamentos definitivos de uma Cultura Administrativa.

Nesse fecundo ponto de vista, há uma relação que merece especialmente ser considerada. E' a relação entre a administração e a vida. Compreendo êsses fatos o Dr. Ludwig Spiegel doutrina: "Bem sabido é que as relações jurídicas são, antes de tudo, relações que se dão na vida. E' evidente que só aquêle que conhece a fundo os fenômenos da vida é capaz de apreender e estudar as relações jurídicas... O Direito Administrativo defronta-se com a vida em tôda a sua plenitude, com tôdas as facetas da atividade humana. Tanto aumentaram, cơm o transcurso do tempo, as funções que o Estado está chamado a realizar, que a Administração poderia muito bem dizer: Nihil humani a me alienum puto. Se isto põe de relêvo a imensa amplitude da matéria que abrange o Direito Administrativo, também explica por que a Teoria da Administração não é capaz de assenhorear-se desta matéria. Apenas há uma ciência que não possa servir de base das normas administrativas. Seria supérfluo insistir com pormenor neste ponto. Bastará indicar que por exemplo, as ciências naturais, históricas, médicas, econômicas, técnicas, e outras disciplinas de que a primeira vista não poderia suspeitar-se esta possibilidade, como as matemáticas servem de base ao Direito Administrativo. Ao serviço da Administração pública encontram-se, de fato, não só os juristas, mas também os representantes de tôdas as demais faculdades, escolas e disciplinas" (Derecho Administrativo, Editorial Labor, S. A.).

Feitas essas considerações preliminares, desenvolvamos o nosso tema de acôrdo com um conceito amplo e arejado de administração, tudo para garantir o advento de uma civilização melhor e mais perfeita.

\section{CULTURA E VIDA}

Trabalhar para viver e não viver para trabalhar. O trabalho foi feito para o homem e não o homem para o trabalho. 
Considerando atentamente êsse ponto de vista, situamos o trabalho no seu verdadeiro lugar, sem diminui-lo nem exagerá-lo. "O trabalho - seja considerado como dever de justiça ou de caridade, ponderou FÉlicien CHALLAYE - é uma obrigação de capital importância. E' um dever que tem o homem para consigo mesmo; o trabalho é a mais formosa manifestação da energia e da inteligência. Quando é moderado, permite gozar melhor das distraçōes sadias e apreciar melhor os prazeres do espírito, as alegrias próprias do descanso. O homem ocioso leva de ordinário, uma existência vazia, malsã e triste. Constitui, antes de tudo, um dever para com a família; o trabalho do homem fora do lar, o trabalho da mulher no lar garantem a vida e a felicidade de tôda a família. E' um dever para com a pátria; a nação não pode conservar ou melhorar a sua situação econômica ou intelectual senão mercê do trabalho dos seus filhos. E', finalmente, um dever que antes de tudo temos para com a humanidade inteira, o dever da solidariedade por excelência; o pôsto que o homem vive graças ao trabalho da humanidade passada e da humanidade presente, deve devolver à humanidade presente e à humanidade futura o que recebeu da humanidade presente e da humanidade passada".

Trabalho e vida não podem deixar de manter íntimas relações, mesmo porque a vida deve ser compreendida no seu dinamismo. Ela sempre muda e se renova. Querer pará-la ou estacioná-la implica em deformá-la, exgotá-la e até aniquilá-la. E é o que acontece em certos povos e em certas épocas. Por isso devemos estar atentos sôbre a diferença entre cultura e erudição. Quando esta se transforma em processo cultural, ou melhor, quando a cultura já não se renova, então, a vida se paraliza e domina o velho, o arcaico e o tradicional.

A cultura não pode perder contato com a vida. A cultura, por vezes, precisa desembaraçar-se de todo artificialismo, para voltar às fontes da vida. ao primordial, ao primitivismo e ao natural.

A vida não deve ser mecanizada, artificializada, presa e fechada, mas necessita permanentemente relacionar-se com as suas raízes, para renovar as fôlhas florir e frutificar. Daí o valor da vida natural, da vida instintiva e mesmo animal. O vitalismo e o irracionalismo alcançam assim a plenitude da sua significação e mostram o exagêro do intelectualismo e do racionalismo. Por isso Nietzch defendeu o instinto, BERGison a intuição, Schopenhauer a vontade, UNAMUNO as paixões, GASSET procurou conciliar a vida com a razão na sua razão vital e KEYSERLING pensou ter encontrado a solução do problema no sentido. A verdade é que, em certas circunstâncias históricas, a cultura precisa vitalizar-se, voltatr à natureza e alimentar as raízes da vida.

Mas a cultura deve orientar-se sempre pelo espírito. Como acentucu PAUl Oltramare: "Viver de modo a tornar a existência, não sòmente para nós mesmos, mas também para os outros, sempre mais ampla, mais rica e mais fecunda; criar a verdade, a beleza, a justiça; esforçar-se por ser poderoso para o bem; fazer da bondade e do amor os motores da sua atividade entre os homens, - é trabalhar conforme o espírito e para o espírito; é cumprir a sua tarefa de homem; é, pelo engrandecimento de si aumentar em si e em tôrno de si a soma e o valor da felicidade; em suma, é fazer frutificar nosso mais precioso tesouro, o único sôbre o qual nós podemos confiar, a vida". Essa necessidade de vida interior aumenta nas épocas anarquizadas, revolucioná- 
rias, profundamente perturbadas, como a nossa, quando a vida exterior não tem organicidade alguma. Então, só a vida interior nos liberta, ordena o ser, acalma e tranquiliza.

A respeito da vida interior muito podemos aprender com a cultura oriental que deve agora harmonizar-se com os valores da cultura ocidental. $\mathrm{O}$ trabalho muito ganharia se relacionasse, em perfeito equilíbrio, a atividade e a contemplação. nunca esquecendo que a vida interior pode ser uma fonte de energia e da mais alta espiritualidade.

\section{CONCEITO EM CULTURA}

Talvez sejamos um dos primeiros estudiosos a tratar da filosofia do trabalho no Brasil. E por isso mesmo desejamos que ela se torne uma filosofia popular, para traçar diretrizes às novas gerações e orientar sadiamente a nossa gente.

A filosofia do trabalho, concebida de acôrdơ com as nossas tradições cristãs, firmada em sólidas bases culturais, consultando os progressos da ciência, da técnica e da filosofia, poderá trazer grandes benefícios à coletividade. Daí a razão dos nossos artigos, que querem definir claramente as relações da cultura com o trabalho de vez que êste é vitalizado, fortalecido e ampliado pelos valores culturais. O trabalho fica assim o fator central da cultura, a sua idéia-síntese e diretriz, que nos permite falar em Cultura do Trabalho. Cormo conseqüência dêsse. ponto de vista, já tratamos da pedagogia do trabalho, civilização do trabalho, humanismo trabalhista, universidade do trabalho e outras tantas concepções congêneres.

Nem todos os doutrinadores, infelizmente, pensam assim. GrovanNI Gentile, por exemplo, sustentou que existe uma antítese radical entre trabatho e cultura. Na sua concepção, o trabalho cria a riqueza e o valor econômico e como tal sempre é reflexo e relativo. A cultura, ao contrário, é um valor verdadeiro e absoluto, porque tem o seu fim nela mesmo. Enquanto o trabalho cristaliza-se num objeto material, físico, determinado, a cultura liberta o homem de tôda sujeição à natureza, de tôda ligação com o espaço e o tempo.

"Tôda essa construção não resiste a uma análise um pouco aprofundada, escreve Adriano Tilgher. Antes de tudo, é falso que a diferença entre Trabalho e Cultura seja a do relativo e do absoluto. A arte, a ciência, a filosofia podem muito bem ser cultivadas não por elas mesmas, mas como um meio para um fim estranho ao ato espiritual que os constitui: desejo de ganhar dinheiro, conquista da glória, ou de uma cátedra universitária ou de uma poltrona acadêmica, e porque não de uma bela mulher, sem por isso deixar de ser arte, ciência e filosofia? Inversamente o trabalho, e não sòmente o do industrial, do comerciante, do banqueiro, mas mesmo o humilde trabalho manual do camponês e do artesão pode muito bem ser exercido não como um meio mas por êle mesmo, em vista de ganhar a paz e a serenidade que se desprendem de um trabalho regulado e disciplinado, realizado com uma alma religiosa e contente.

Não existe meios e fins que sejam meios e fins em si e por si; tudo pode ser meio ou fim, conforme o espírito que o estabelece como tal". 
Sustentamos, pois, a nossa concepção da Cultura do Trabalho. Há evidentemente, um trabalho superior, qualificado, bem feito, bem acabado, que se utiliza de todo o relho da cultura. E' o trabalho que deve doutrinar a Universidade do Trabalho. Trabalho de base científica, artística, técnica, moral, religiosa e filosófica. E' um trabalho correto, preciso, exato; um trabalho belo e harmonioso; um trabalho honesto e digno; um trabalho universal de valor permanente.

\section{CULTURA E ERUDIÇÃO} aquela.

A erudição é necessária à cultura mas esta não deve ser orientada por

A cultura deve ser orientada pela vida, dominada pelos interêsses do momento, simplificada pela inteligência e espiritualizada. Entretanto, a carga da erudição, o intelectualismo vazio, o artificialismo, o excesso de saber sem utilidade, tudo isto asfixia a verdadeira cultura que deve ser inspirada pela vida e pelo espírito. A propósito dêsse assunto, NIETzSCHE externou conceitos profundos e fêz observações de grande valor. Disse o famoso filósofo alemão" "Eu não escrevo tratados; êstes são para os asnos e para os leitores de jornais... Outra sabedoria e defesa de si mesmo consiste em reagir as menos vêzes possível, subtrair-nos das situações e das condições pelas quais nos veríamos condenados a suspender de certo modo nossa liberdade, nossa iniciativa, para vir a ser um simples órgão de reação. Tomo qual têrmo de comparação as nossas relações com os livros: o sábio que em suma se contenta com "remover" volumes (no filólogo de disposições médias esta cifra se eleva a uns 200 por dia), êsse sábio acaba por perder completamente a capacidade de pensar por si mesmo. Se não revolve já volumes não pensa; responde a uma excitação (uma idéia que lê) quando pensa e, finalmente, se contenta com reagir. O sábio gasta tôda a sua fôrça em aprovar e em contradizer, em criticar coisas que foram pensadas por outros que não êle; porém êle mesmo não pensa jamais... O instinto de defesa debilitou-se nêle, ao contrário, pôr-se-ia em guarda contra os livros. O sábio é um decadentet. Eu vi com os meus próprios olhos naturezas bem dotadas, de abundante e livre disposição, que quando chegaram aos trinta anos se arruinaram pela leitura. São semelhantes aos fósforos de cêra, aos quais é necessário esfregar para que dêm luz, "idéias". Logo nas primeiras horas da manhã, quando o dia começa, quando o espírito possui tôda a sua frescura, quando a fôrça está na sua aurora, ler então um livro eu chamo isto de vício!"

A erudição, pois, a simples erudição por si mesma não representa grande valor cultural e tem todos os perigos acima apontados. Só o espírito aligera, torna flexível e maleável a cultura. Esta, como nunca nos cansamos de repetir, é vida, criação e atividade; é um fundo substancial, cujo conteúdo incessantemente pode aumentar de acôrdo com as necessidades adaptativas. Além de rico conjunto de recursos para investigar a verdade e agir eficientemente, constitui preciosa fonte de íntimas satisfações pessoais. Cultura é vida. Vida é adaptação; adaptação crescente e perfectível e por isso promove o progresso, o qual para se garantir a continuidade, implica sejam satisfeitas a novas exigências surgidas. 
Por essa razão, o problema da atualidade, de carátèr nacional e acentuadamente universal, é o da cultura.

Mas a cultura é um processo adaptativo integral è como implica esfôrço e energia, constitui poderosa fôrça de edificação pessoal e coletiva. Ela, na sua finalidade mais palpável, é esperança, e a esperança é um raio de luz que ilumina as trevas. Cultura é orientação, e, como tal, habilita-nos a compreender, viver e ativar o mundo. Assim nos aclara a conduta, desenvolve as energias e as estimula, impulsionando-nos à atividade. Cultura é vida, mas vida na sua expressão ampla. na sua inteireza; é vida rica e fecunda, voltada principalmente para a realização de magnos ideais, fonte perene de todo progresso. O maior mérito da cultura é o trabalho honesto e inteligente. Êle tudo resolve e consegue. Por isso o seu valor, socialmente, cada vez mais deve ser apregoado. Êle dignifica o homem reabilita a quem erra; eleva a pessoa e enaltece os povos, engrandecendo a civilização.

Em outros estudos, faremos considerações mais pormenorizadas sôbre o trabalho intelectual.

\section{CULTURA E ENCICLOPÉDIA}

O trabalho é uma realidade tão grandiosa e magnífica que precisa de uma universidade para propagar os seus princípios e leis.

Foi por isso que em Genebra, na Organização Internacional do Traba1ho, em 1952, lancei a idéia de uria Universidade Mundial do Trabalho, espécie de uma super-universidade, que deveria reunir, numa unidade, tôdas as instituições que tratam do trabalho, para organizá-lo no planêta, estudando cientìficamente as suas condições geográficas, históricas, sociológicas e culturais. Teríamos assim uma entidade prestigiosa que poderia ser verdadeiro cérebro mundial do trabalho, para garantir, em todos os países um trabalho ordenado metódico e organizado, combatendo o esfôrço humano desordenado, caótico e cheio de conflitos. Um trabalho rendoso, produtivo e fecundo poderia construir a paz tão almejada:

Tal universidade poderia realizar a Enciclopédia Mundial do Trabalho. Tive essa idéia. lendo o livro de H. G. Wells - The Work, Wealt and Happiness of Mankind. O famoso escritor inglês, depois de estudar o movimento enciclopedista desde Aristóteles até Diderot, detendo-se em considerações sôbre a Enciclopédia Francêsa e a Enciclopédia Britânica, conclui que a nossa época tão necessitada de conceitos gerais diretores precisa, agora, de uma Enciclopédia Mundial: "A enciclopédia do futuro terá de ser obra duma grande organização que empregue permanentemente milhares de colaboradores e gaste milhões de libras por ano; uma obra de mediação entre o pensador original, o investigador científico, o estadista, o trabalhador de faculdades criadores e o repórter das realidades de um lado e o público de outro. Mas tal organização superará em influência e escala qualquer universidade existente, e sem dúvida tirará da direção do mundo o frouxo sistema universitário existente". Inspirado por essas idéias, WELLS redigiu a sua obra, que tem os mesmos objetivos de divulgação que a sua História Universal. Por isso assim se exprime: "Esta obra se propõe a ser um retrato da humanidade de hoje um quadro da massa humana que trabalho, que gasta, que constrói e destrói. 
Existem, supomos, cêrca de 1.900 milhões de sêres humanos. Todos respiram, comem, dormem e se empenham nas mais variadas atividades. Cooperam uns com os outros e vivem em conflitos uns com os outros. Morrem, mas são contìnuamente substituídos pelos que nascem. Procuramos nesta obra dar o quadro de tôdas as atividades humanas. E depois, à medida que o panorama se fôr desdobrando, proporemos respostas às questões que naturalmente emergem do espetáculo. Que é que sustenta esta universal atividade? Porque vivem êsses milhões de criaturas e como vivem? Quais as várias maneiras de vida e quais os motivo's que as determinam? E' o que procuramos expor e elucidar. Depois do "Como", o "Por que?".

Um quadro assim não foi tentado nunca. E nem sequer seria possível, antes da nossa era. Nem possível nem útil. Hoje, porém, não só se tornou possível como indispensável. Nunca, como hoje, foram mais intensas a necessidade e a ânsia de conhecer o mundo como um todo. Essa necessidade e essa ânsia nos sobrevieram de súbito".

A iniciativa de WELLS merece a atenção de todos os povos cultos. Ela tem por fim ampliar, desenvolver e fazer crescer a idéia do trabalho. Daí podermos pregar também os diferentes valores para êste elevado objetivo e têrmos assim uma ciência, uma arte, uma técnica, e enfim. uma cultura do trabalho. O trabalho deve ser a idéia central, a idéia matriz e a idéia síntese de todo o sistema. Essa reflexão faz tudo gravitar em tôrnơ do trabalho.

O trabalho é um cosmos. O principal é precisar a sua idéia. Enriquecê-la. Nutri-la. Fortalecê-la. Fazê-la brilhar.

O trabalho é um sol. Êle ilumina a vida inteira. As suas concepções assim são fecundas, brilhantes e magníficas.

\section{CONGRESSO DE CULTURA}

O trabalho, em virtude da excepcional importância que possui na civilização moderna, necessita de ser estudado em todos os seus aspetos. Por isso mesmo certa vez imaginei a possibilidade da realização de um Congresso de Cultura do Trabalho no Brasil, com a finalidade de reunir os nossos mais eminentes juristas, sociólogos. educadores, economistas, políticos, engenheiros e pensadores com o objetivo de estudarem juntos os problemas nacionais com critério realístico e cultural, dando um balanço em tudo o que o nosso país já realizou nos diversos setores da atividade humana, para se poderem assim traçar diretrizes ao trabalho nacional, com a intenção de congregar esforços em tôrno de uma obra comum.

O temário dêsse Congresso poderia ser mais ou menos o seguinte:

$1^{\circ}$ ) Direito do Trabalho - Os seus problemas atuais. A participação nos lucros. Organização sindical. A extensão da legislação trabalhista ao empregado rural. O código do trabalho. Reforma da Previdência Social e Re. forma do Ministério do Trabalho

$2^{\circ}$ ) Educação do Trabalho - O ensino técnico-profissional. A mentalidade trabalhista. $\mathrm{O}$ trabalho de direção e o trabalho de execução. Fundamentos de uma pedagogia do trabalho; 
3. ${ }^{\circ}$ Economia do Trabalho - O trabalho na agricultura, no comércio, e na indústria. A produção e a distribuição da riqueza. A crise do trabalho;

$4^{\circ}$ ) Política do Trabalho - A legislação social em face da Constituição Brasileira. A vida sindical. A organização do trabalho na democracia. Valorização da nossa gente e da nossa terra;

5. ${ }^{\circ}$ Técnica do Trabalho - A máquina na época atual. O problema do combustível no Brasil. Recursos da técnica moderna;

6. ${ }^{\circ}$ A Filosofia do Trabalho - A cultura do trabalho. A civilização do trabalho. A questão social. O sentido do trabalho. O humanismo do trabalho.

Cumpre esclarecer aos interessados que a escolha das teses, de acôrdo com o temário acima seria inteiramente livre. O congressista poderia estudar qualquer problema do trabalho, aquêle que mais the conviesse, mantendo-se, porém, sempre fiel ao espírito do conclave, cuja finalidade seria firmar as bases de um humanismo do trabalho, pelo exame das relações do trabalho com os demais valores culturais, como a ciência ${ }_{4}$ a arte, a filosofia e a religião, para evidenciá-lo como o fator decisivo da civilização. A humanidade precisa compreender, custe o que custar, que o trabalhơ não é só um fator econômico, mas é também e principalmente, um fator moral, jurídico, religioso e social.

O trabalho, dêsse modo entendido, renovaria o mundo. Ele sempre fci o maior elemento do progresso, pois, povoou a terra, conquistou o mar e dcminou o céu. A própria civilização é o trabalho realizado de todos e de cada um, no presente como no passado, assim como o será no futuro. O trabalho não poderá ser mais pena e escravidão, mas sim, domínio e libertação. O trabalho prestigiado mudaria a hierarquia dos valores sociais. porque só êle, quando obrigatório a todos, democratiza a sociedade, melhorando-a.

Dentro dessas normas, o mencionado Congressa poderia estabelecer um humanismo do trabalho, que permitiria a compreensão da época como possibilitaria os meios da solução dos seus grandes problemas. Tal conclave daria oportunidade a todos os homens cultos do Brasil de se fazerem ouvir a res. peito dos magnos problemas nacionais, apresentando soluções, traçando diretrizes e auxiliando os poderes governamentais a bem agirem nos mais diversos setores da administração.

Fica aí a iniciativa dêsse original congresso, que não seria fechado a uma classe de especialistas. Não. Todos os profissionais e técnicos, dos mais variados setores, poderiam participar dêle, e trazer as suas luzes. Seria um congresso que exigiria a cooperação de todos. de vez que é para todos, tanto para o povo como para a elite, para o advogado, médico, jornalista, cientista e filósofo como para o operário e o trabalhador em geral. Todos poderiam acompanhar a sua realização e interessar-se vivamente por êle.

\section{CULTURA E CIVILIZAÇÃo}

A civilização é o produto da cultura. Esta constitui a fôrça civilizadora por excelência. Ora, a cultura cria a civilização, e esta é consequência daquela através do trabalho. 
O trabalho realiza a civilização e esta representa sempre o esfôrço acumulado de todos os tempos. "O trabalho cura o homem da tentação da guerra, afirma E. BORNE e F. HENRY, entendendo por sociedade civilizada aquela em que um poder espiritual é capaz de transformar ơ guerreiro em agricultor e pastor. A guerra põe em jôgo instintos espontâneos e violentos; o trabalho é pacífico; pede tempo ordem e precisão; é a aprendizagem das virtudes mães da civilização. O trabalho é o guardião das paixões congênitas do homem que são a guerra e o aborrecimento; ensina-lhe a portar-se bem com as cousas e com os homens. A filosofia realista e paciente do trabalho está simbolizada pela história da tela de Penelope que desalenta aos pretendentes, algo assim como o trabalho desalenta às paixões veementes e desordenadas, às tentações vulgares ou sutis da ociosidade. $\mathrm{O}$ amor ao trabalho consiste menos no amor ao ademão laborioso que no amor aos valores morais e civilizadores que põe na vida de todos e de cada um. Já podemos fazer menos incompleta a de finição do trabalho: "Chamo trabalho ao esfôrço criador de bens úteis, isto é, ao esfôrço que se põe ao serviço de uma obra destinada de por si ao serviço da humanidade, que é por sua origem um esforç̧o pessoal, e por seus fins, fraternal".

Dentro dessas considerações, meditemos sôbre a civilização moderna e sôbre as possibilidades de cada vez mais humanizá-la e melhorá-la. Realmente, de como humanizá-la? Eis o grande problema que absorve a atenção dos maiores pensadores do mundo todo, problema que também nos particularmente tem interessado, como demonstramos em diversos livros.

O meio mais eficaz de atingir aquêle objetivo, inegàvelmente, é o perfeito conhecimento do homem; êle deve ser a medida de tôdas as coisas. Mas o homem não é simples agregado de células, unidas transitòriamente por mera casualidade; êle deve garantir a sua posição de superioridade na escala zoológica. Como vive numa determinada sociedade, para a qual tem deveres e obrigações a cumprir a sua vida precisa adquirir significação, para ser fecundada e feliz. Essa exigência, desprendida da própria natureza humana, é um imperativo categórico. E' mister cúmpri-la, para entrarmos em harmonia com o mais íntimo do nosso sêr.

Nesse sentido, a vontade constitui um dos atributos mais elevados do homem. Este, consciente de que a sua ação não é destituída de significação, igualmente sabe que a sua personalidade representa algo de valioso na sociedade e no mundo. Por essa razão aquêle que, não poupando esforços para realizar os seus fins, se domina a si próprio, chegando até a se violentar, é digno da nossa mais profunda admiração. As grandes conquistas da humanidade são devidas a êstes espíritos perseverantes e superiores.

O homem não é, pois, só egoismo, pobreza e miséria. Não. Êle também possui uma dignidade, que dimana da consciência da sua individualidade intrínseca. E' nesse ponto de vista, no da sua essência superior, que temos de o encarar. Assim, não procederemos como aqueles que, analizando-o ùnicamente na sua parte material, dividiram e dissecaram-no, mas não viram a nobreza da sua superioridade e a sublimidade das suas altas exigências espirituais. O homem foi esquecido, e o animal lembrado. Por outro lado, fato que lamentàvelmente se tem negligenciado, o homem não é só entendimento. 
O complexo do seu sêr, ao contrário, é rico conjunto de faculdades sôbre as quais pode exercer certo domínio: Cada uma delas tem funções peculiares. Uma não pơde ser absorvida por outra, e cada qual deseja persistir no seu sêr.

Assim o desenvolvimento exclusivo de uma faculdade vem em detrimento das outras, resultando, como consequeencia necessária, o rompimento da harmonia espiritual. A unidade individual, a alma, então é esfacelada, dividida e deslocada, e os elementos dispersos sem coesão alguma, no todo, são destituídos de fôrça. Nstas condições, não sentimos o nosso sêr na sua plenitude, e a vida não adquire sentido. Não basta, pois, para satisfazer as exigências humanas o cultivo do intelecto, da memória, da razão; é mister ainda cuidar dos sentimentos, da imaginação, criadora da vida afetiva com tôda a sua beleza. Acresce a essa verdade uma outra de não menor importância. E' à distinção entre a razão, tomada no sentido restritơ e no sentido lato. Esta compreende o todo da espiritualidade e aquela é a razão, enquanto se exercita por assimilar os fenômenos científicos.

Daí se deduz que o homem tem outras exigências mais imperiosas além das de razão restrita. Baseado nesta realidade indiscutível, reconhecida, no entanto, por poucos, Boutroux procura resolver o difícil problema das relações entre o espírito científico e o espírito religioso, vendo na vida o traço de união entre a ciência e a religião. Dêste modo, a ciência não é o todo do homèm; algo mais existè que lhe é necessário, e, não obstante, não thé é proporcionado nos tempos atuais. Daí resulta a inquietação e a insatisfação : E êstes são os prejuízos mais graves da nossa época.

O homem moderno, por exemp'ó, pelo exceśsivo e exclusivo desenvolvimento do intelecto, ficou pouco ápto para a receptibilidade dos gozos estéticos, que de mais encanto e beleza revestem a existência, tornando-a boa e suportável.

Como corrigir êsses defeitos? Como resolver essas dificuldades? E' possível alguma melhora nas condições da vida social moderna? E se há tais possibilidades, de como realizá-las?

A verdadeira cultura responde a tôdas essas interrogações e soluciona em justa medida, os problemas relativos a êsse difícil assunto, cuja complexidade intrínseca preocupa a maioria dos pensadores. A integração do sêr, como domínio pessoal e consciência da própria individualidade, tem por fim a unidade e a harmonia espiritual; ela é, ademais, o desenvolvimento harmonioso das faculdades humanas, tendendo para os elevados fins ideais da vida. Os homens sentirão. dêste modo, a plenitude das suas fôrças; ser-lhes-á, particularmente, permitido satisfazer as necessidades morais e estéticas, que tantos prazeres e alegrias trazem à vida, dignificando e embelezando-a. E' assim que se poderá combater com máxima eficácia a nostalgia e o fastio ainda hoje reinantes, determinados pela preponderância de uma cultura sem alma, dura e sêca, puramente material.

Dêsses princípios concluímos que para harmonizar os nossos tempos é mister humanizar a nossa civilização mecanizada. O homem deve ser a medida de tôdas as coisas, e assim a civilização é que deve tomar a sua confi- 
guração humana. Nunca nos esqueçamos. porém, que a humanidade progride pelo trabalho inteligente; a civilização constitui, apenas, em última análise. o produto do trabalho armazenado das gerações passadas e presentes:

\section{TRABALHO E ADMINISTRAÇÃO}

A melhor maneira de estudar as relações evidentes entre o trabalho e. o dever é afirmar que o trabalho é um dever, fato êste hoje universalmente reconhecido pelos povos cultos, que fazem questão de sustentá-lo nas suas respectivas Cartas Magnas. A nossa Constituição, por exemplo, no parágrafo único do art. 145 dispõe: "A todos é assegurado trabalho que possibilite existência digna. O trabalho é obrigação social". A lição de São Paulo triunfou. Quem não trabalha não deve comer. Por isso agora o trabalho constitui um dever e um direito do indivíduo para com a sociedade e vice-versa.

Todos os países adiantados compreenderam que o trabalho é um dever social. Através dêle o indivíduo contribui para o progresso da sociedede empregando as suas fôrças físicas e mentais no desenvolvimento da produção da riqueza ou da criação dos valores na ampla esfera da cultura. Nada assim é mais condenável que o parasitismo, a exploração do esfôrço dos nossos semelhantes e a desocupação voluntária, que não deixa de ser crime.

Estudando êsse delicado problema, WILHELM SAUER chegou à conclusão que a questão obreira só pode compreender-se e resolver-se, atendendo à essência e valor do trabalho. O trabalhador deve participar de todos os modos, dos valores da cultura. "Tôdas estas medidas, doutrina o jurista e filósofo alemão, hão de estar orientadas no sentido da finalidade última dotada de validade universal, da que derivam a sua justificação íntima e por cuja substância hão de estar completas, pôsto que elas mesmas não podem nunca ser exaustivas. Porém elas por si sós não darão nunca satisfação ao homem. Por isso se falta êsse elemento último, supremo, que é o único definitivo, a mais perfeita reforma concreta não será mais que um degrau (e, na verdade não é outra coisa); o trabalhador exigirá sempre salário mais elevado, melhor habilitação, férias mais largas, e exigirá cada vez mais. Sempre ficará descontente: não logrará verdadeira satisfação enquanto não se lhe faça ver - . falando ao homem ingênuo uma linguagem compreensível - que trabaiha para o conjunta cultural e nacional, que no seu trabalho radica o sentido da sua própria vida, que o descanso não se acha depois do trabalho, senão no trabalho mesmo, que os valores por êle criados, por insignificantes que pareçam em relação com a totalidade, passam à Cultura e, portanto à eternidade, que constituem uma imortalidade e conduzem à Divindade. Por isso acompanha a seu trabalho a benção de Deus".

Ponderando bem tal argumentação, concordamos com VALTOUR: "Cravamós em mármores e bronzes a lista dos direitos do homem. Necessário seria gravar em ouro a dos seus deveres". E isto porque, como sustenta RoDRIgUEZ RUBI: "Se cada qual cumprisse com os seus deveres, êste mundo não seria um vale de lágrimas; seria o verdadeiro Paraíso terrestre". ROBERTSON DE BRIGHTON tem razão: "A verdadeira grandeza do homem não consiste 
em procurar-se prazeres, ou celebridade, ou dignidades, nem em prover à salvação da vida, nem em coroar-se de glória, mas em cumprir o próprio dever".

O trabalho é um grande dever social, uma exigência imperiosa da sociedade, uma necessidade vital. Ninguém pode viver sem trabalhar, porque o trabalho é a própria razão de ser da vida. O Estado moderno, por esta razão. concede ao trabalhador todos os direitos, mas lhe exige, por sua vez, exata compreensão dos deveres, deveres êstes que dizem respeito à Pátria. Êsse imperativo se enriquece de sentido, mormente agora, em nossos dias quando vivemos numa época dolorosa de tragédias coletivas com a aniquilação de povos e nacionalidades. O trabalho é o construtor das grandes pátrias. Êle agrega um povo em nação. De mister se faz, por êste motivo, educar as nossas classes trabalhadoras, para torná-las fatores conscientes da grandeza nacional.

O Brasil, atualmente, necessita muito de trabalho coletivo e harmônico de todos os brasileiros. Tal trabalho implica disciplina autoridade e um elevado objetivo comum. O trabalho sob o impulso de um ideal forte não conhece tédio, consaço nem fadiga. Êle vence todos os obstáculos e ruma direito para a realização. E' êsse trabalho que traz consigo a felicidade humana, felicidade nacional.

\section{CULTURA ADMINISTRATIVA}

Finalizamos com reflexões, concluindo pela necessidade de relacionar intimamente os conceitos de trabalho; cultura e administração, dentro de um critério de polarização mental, com o objetivo específico de desenvolver a cultura administrativa.

O trabalho recebe poderosos estímulos da polarização. Cơmo bem observou Goethe: "O igual deixa-nos em repouso; a contradição, porém faz-nos. produtivos".

A polarização é um fenômeno cósmico e universal, que se encontra em tôdas as manifestações naturais ou espirituais, dinamizando sempre os processos energéticos por tensões especiais. Nos fenômenos de eletricidade ou. magnetismo é fácil verificar-se o papel do polo positivo e do polo negativo. Cada polo evoca a identidade do outro, para produzir os seus efeitos. Com o conhecimento das leis da polarização, podemos perfeitamente pensar numa ciência, numa arte e numa técnica da polarização. O principal está em reconhecer os seus fatos característicos, como por exemplo, em diferentes planos, a polarização dos sexos, a polarização das personalidades, a polarização do. indivíduo com a sociedade, a polarização de um continente com outro, a polarização do Oriente com o Ocidente, enfim, a polarização com o mundo inteiro e até com Deus.

Na sua Escola de Sabedoria. KEYSERLING visava a polarização das personalidades, e por isso estudou em diversos trabalhos os mistérios da polarização. Assim afirmou: "A polarização recíproca dos espíritos individuais não é evidentemente senão uma das vias que conduzirá largamente à criação de um nível espiritual superior. Porém dado o espírito analítico da Europa contemporânea, é acaso o que há de mais necessário ao princípio do processo. E' preciso, para começar, que o espírito pessoal de cada um não detenha para: 
si mesmo a sua própria última instância, que aceite outras como partes integrantes do seu próprio ou superior: enquanto essa meta não seja alcançada, não poderá nascer um tipo de homem de envergadura mais vasta como não o é o europeu tradicional. Porém a minha Escola da Sabedoria não ensina ùnicamente a polarização com outros indivíduos: ensina a polarização com o mundo inteiro; ensina a dar-se completamente a tôda experiência, e aceitar sem reservas o Todo da Vida, sempre em vista de uma integração pessoa! ferpètuamente crescente que em seu limite levaria ao alargamento do eu até os confins do Universo".

No livro O Culto da Grandeza, doutrinamos o desenvolvimento da personalidade através da polarização do nosso eu com os grandes gênios da humanidade. Compreendê-los é estar à altura dêles. Por isso êsse culto é um culto muito sério. Ninguém penetra na alma de um grande sêr sem simpatia, amor, devoção, respeito, consideração e estima. Uma alma elevada exige que nos elevemos. A polarização aqui não é imitatção, mas afirmação do próprio sêr. Quem imita renega a sua essência, e perde o seu valor peculiar.

No ensaio A Grandeza da Mulher, acentuamos esta verdade. A mulher não deve imitar o homem. Quando ela se masculiniza, dissipa-se a essência perfumada do feminino. Quando o homem se feminiza, a sua virilidade fica comprometida. Então. o homem deixa de ser homem e a mulher de ser mulher. Eis a tragédia dos sexos. A normalidade está no princípio de que os opostos se atraem. A mulher só interessará o homem profundamente, quando retornar à feminilidade.

Os fenômenos da polarização exigem exata compreensão. Devemos ser compreensivos, isto é, receptivos, tolerantes e cheios de boa vontade. Não é possível compreender sem simpatizar e amar, sem pensar e raciocinar, sem desejar e querer. Em qualquer plano da compreensão, precisamos ser receptivos intuir e perceber as coisas, sem negar ou rejeitar a priori, mas sim, com a preocupação de afirmar e aproximar. A compreensão traz a colaboração, cooperação, solidariedade, harmonia e paz entre os homens. Ela constitui um imperativo de ordem moral, social e cultural. De nada vale a filosofia que não aumenta a nossa compreensão.

\section{SUMMARY}

1. Administration should be conceived in its relationship with science, art, technology, ethics and philosophy, in order that the definitive foundations of an administrative culture might be laid.

2. The link between administration and life. The ever-increasing scope of the func. tions of the state. Every science, natural, historical, medical, economical, etc., summoned to the service of administrative law.

3. The concept and value of labour. Labour as a duty. The relationship between life and labour. Life and labour should not be mechanized or artificialized. Culture is hased on spiritual values.

4. The philosophy of labour conceived acording to our Christian traditions. Labour as the central factor of culture. The idea of a labour culture. The false antinomy between labour and culture. 
5. Erudition as necessary to culture. Yet the latter should not be directed by the former but rather inspired by life. The danger of erudition per se.

6. The project of a World Labour University advocated by the author in Geneva (1952). The University should edit the World Labour Encyclopaedia.

7. The proposed Congress of Labour Culture to be eventually held in Brazil. A tentative agenda for it: (1) The right to a job; (2) Vocational education; (3) Labour economy; (4) Labour policies; (5) Technologly of Labour; (6) Philosophy of Labour.

8. Civilization and culture. Labour as an agent of civilization. Labour as a weapon against war and uncontrolled passions. The necessity of humanizing our mechanized civilization through a perfect knowledge of man and of his potentialities and virtues to be harmoniously developed. Modern man has developed his mind but neglected other faculties, especially the artistic.

9. Labour as a social duty. The duty to work should be stressed side by side with the right to work. Brazil needs the cosperative and harmonious efforts of every citizen.

10. The development of an administrative culture through the polarization of labour, culture and administration. Polarization requires understanding, receptivity, tolerance and €ood-will. All this will result in collaboration, cooperation, solidarity, harmony and social peace.

Do que foi a administração pública no Brasil até fins do século XVIII bem nos contam vários estudiosos do assunto, como Olvieira Viana, Pandí́ Calógeras e outros. Foi um predomínio da corrupção mais absoluta, a par de uma negligência quase integral pelos destinos da colônia. Os que vinham de Portugal ocupar cargos administrativos no Brasil, só traziam um objetivo: enriquecer o mais depressa possível e regressar à Metrópole.

José Alípio Goulart - Sociologia e Administração Pública no Brasil - In "Revista do Serviço Público" - Volume I - n. 3 , Março de 1954 - página 39. 